\title{
ANÁLISE DAS PRODUÇÕES TEXTUAIS NO EXAME CELPE-BRAS: SUBSÍDIOS PARA UMA AVALIAÇÃO FORMATIVA DA ESCRITA ${ }^{1}$
}

\section{ANALYSIS OF TEXT PRODUCTIONS IN THE CELPE-BRAS EXAM: SUBSIDIES FOR A FORMATIVE ASSESSMENT OF WRITING}

\author{
Lívia Cristina Virgolino da Silva² \\ Myriam Crestian Cunha ${ }^{3}$ \\ Universidade Federal do Pará
}

\begin{abstract}
RESUMO
Neste estudo tivemos como propósito gerar subsídios para a avaliação formativa da escrita por professores-estagiários de turmas de preparação ao exame Celpe-Bras (Certificação da Proficiência em Português para Estrangeiros). Para isso recorremos a documentos oficiais sobre o exame CelpeBras, a estudos sobre gêneros discursivos e seu ensino (na linha dos pesquisadores em didática da Universidade de Genebra) e a estudos sobre avaliação formativa em língua (na perspectiva francófona). Quanto à metodologia realizamos uma pesquisa documental, em que analisamos 88 tarefas de produção escrita do exame Celpe-Bras realizadas entre 2005 e 2015, de modo a depreender suas características, em relação às situações discursivas predominantes. Os resultados evidenciam uma produção pautada em tarefas que levam o examinando a interagir socialmente, no contexto das situações de uso simuladas pelo exame, obtendo informações de textos orais e escritos e produzindo textos escritos que pertencem preferencialmente a gêneros do grupo "argumentar", com preferência para o registro formal da língua. Uma grade de critérios e seus descritores foi elaborada para fins de avaliação formativa e está sendo testada nas aulas de preparação ao exame e na formação dos estagiários.
\end{abstract}

PALAVRAS-CHAVE: Celpe-Bras; gêneros discursivos; produção escrita; avaliação formativa.

\begin{abstract}
This study aims to generate aids for a formative assessment of writing for teachers-trainees in preparation classes to the exam Celpe-Bras (Certificate of Proficiency in Portuguese as a Foreign Language). For this we resort to readings about this examination, about speech genres and its learning (according to researchers at the University of Geneva) and about formative assessment in language learning (in Francophone perspective). Regarding the methodology we conducted a documentary research in which we analyzed 88 tasks of Celpe-Bras examination writing production accomplished between 2005 and 2015, in order to point their characteristics in relation to the prevailing discursive situations. The results show tasks guided writing which lead the examinee to interact socially in the context of use situation simulated by the test, by obtaining information from oral and written texts and by writing texts that belong preferably to the group of argumentative genres, with preference for formal language. A grid of criteria and their descriptors, developed for formative assessment purposes, is being tested in the exam preparation classes and in training for teachers-trainees.
\end{abstract}

\footnotetext{
1 Trabalho desenvolvido com o apoio do Programa PIBIC/FAPESPA.

${ }^{2}$ Licenciada em Letras pela Universidade Federal do Pará. E-mail: liviavirgolino@hotmail.com

${ }^{3}$ Doutora em Ciências da Linguagem pela Université de Toulouse II. E-mail: $\underline{\text { mycunha@,ufpa.br }}$
} 
KEYWORDS: Celpe-Bras; discursive genres, writing; formative assessment.

\section{INTRODUÇÃO}

Neste trabalho, abordamos a produção escrita, tal qual exigida nas tarefas do Certificado de Proficiência em Língua Portuguesa para Estrangeiros (doravante Celpe-Bras), na perspectiva da avaliação formativa praticada no cotidiano das aulas de preparação ao referido exame.

Essas aulas são ministradas a alunos estrangeiros do convênio PEC-G ${ }^{4}$, acolhidos todos os anos em nossa universidade para se preparar ao exame. Ingressam como iniciantes completos em uma turma de Português como Língua Estrangeira (doravante PLE), mas, ao término de oito meses de aprendizagem, com 20 horas semanais de aula, precisam ter alcançado o nível de certificação Intermediário para poder, então, se matricular em um curso de graduação numa IES brasileira.

Essa preparação em ritmo intensivo é particularmente desafiadora, pois: a) na parte escrita do Celpe-Bras, o examinando deve produzir quatro textos adequados às situações propostas, para que suas habilidades de compreensão oral e escrita e de produção escrita sejam avaliadas de forma integrada; b) o trabalho com esses estudantes estrangeiros constitui uma atividade de extensão, na qual intervêm alunos-estagiários voluntários (eles mesmos estudantes de licenciatura em uma língua estrangeira) que, muitas vezes, ainda não têm formação suficiente para guiar o desenvolvimento das habilidades solicitadas; c) finalmente, o material didático para aprendizagem do PLE, disponível no Brasil, não se destina à preparação para o exame e, sendo assim, não ajuda nem os estagiários, nem os alunos estrangeiros a entenderem como os textos produzidos serão avaliados.

O presente estudo foi empreendido, pois, com o propósito de gerar subsídios - na forma de informações estruturadas a respeito das características predominantes das tarefas que compõem a parte escrita do exame - para propiciar uma avaliação efetivamente formativa das produções textuais desses alunos ao longo da aprendizagem.

Descrevemos a seguir o exame Celpe-Bras, cujas tarefas escritas serão objeto de análise, e expomos a base teórica deste estudo relativa à noção de gêneros e de avaliação formativa no ensinoaprendizagem de línguas.

\section{As tarefas no exame Celpe-Bras}

Segundo documentos oficiais do Instituto Nacional de Estudos e Pesquisas Educacionais Anísio Teixeira (INEP), órgão ligado ao MEC e responsável pelo gerenciamento do exame, o Celpe-Bras se constitui como o único certificado de proficiência em português reconhecido pelo governo brasileiro (BRASIL, 2013)5. A certificação é realizada em quatro níveis de proficiência, usando-se, para isso, um único instrumento de avaliação6.

A premissa do exame é julgar o examinando de acordo com a qualidade com que este atua em língua portuguesa. De fato, as provas caracterizam-se pela "ênfase no uso da língua; o uso de textos autênticos; a avaliação integrada de compreensão e produção (oral e escrita)" (BRASIL, 2013, p. 5).

\footnotetext{
${ }^{4}$ O Programa Estudantes Convênio Graduação (PEC-G) é mantido pelo Ministério da Educação brasileiro com apoio do Ministério das Relações Exteriores, com base em acordos de cooperação educacional com países da África, da América latina e do Caribe. Quando os candidatos ao programa não podem submeter-se ao exame em seu país de origem, eles têm a possibilidade de se preparar para o exame em aulas ministradas em uma universidade brasileira.

${ }^{5} \mathrm{O}$ exame é aplicado, hoje, em 94 postos distribuídos por 35 países, com o propósito de certificar a capacidade de uso do português por falantes não nativos dessa língua (BRASIL, 2016).

${ }^{6}$ Em função do desempenho apresentado, os examinandos recebem a certificação em nível Intermediário, Intermediário Avançado, Avançado e Avançado Superior. O nível Básico não é certificado.
} 
A parte escrita do exame, com três horas de duração, é composta por quatro tarefas que, como explica Schoffen (2009, p. 35-36), avaliam a proficiência pela capacidade de ação envolvendo a linguagem:

[O foco está na] capacidade de agir no mundo em situações similares às reais, possíveis de acontecer com pessoas que utilizam a língua portuguesa para se comunicar - [o exame Celpe-Bras] é, portanto um teste de desempenho [que] avalia as práticas de compreensão oral, leitura e produção escrita através de tarefas.

No Guia do Participante (BRASIL, 2013, p. 7), a tarefa é caracterizada como "um convite para agir no mundo, um convite para o uso da linguagem com um propósito social". A ação pretendida realiza-se por meio da linguagem e das formas textuais socialmente reconhecidas: Cada tarefa solicitará que o examinando se coloque em determinada posição social (enunciador) e, a partir dessa posição, compreenda o texto (oral, escrito ou multimodal) apresentado, selecione as informações adequadas e escreva a uma determinada pessoa ou grupo de pessoas (interlocutor) a fim de realizar uma determinada ação (propósito). São os elementos da tarefa que delimitam para o examinando as condições de produção de leitura e escrita, construindo um texto pertencente a determinado gênero do discurso, ao mesmo tempo em que fornecem os parâmetros para a avaliação (BRASIL, 2013, p. 7).

Ao usar a linguagem com um propósito social, nessas tarefas, o candidato é levado a redigir textos pertencentes a determinados gêneros discursivos ${ }^{7}$. Apresentaremos agora esse conceito que não só pauta a realização das tarefas no exame Celpe-Bras, como também está bem presente no ensino de línguas estrangeiras.

\section{Gêneros no ensino-aprendizagem de línguas}

Para falar dos gêneros discursivos utilizados na interação entre membros de uma sociedade, Marcuschi (2007, p. 22-23), apoiado em Bakhtin (1997), propôs uma definição que se tornou clássica: "uma noção propositalmente vaga para referir os textos materializados que encontramos em nossa vida diária e que apresentam características sócio-comunicativas definidas por conteúdos, propriedades funcionais, estilo e composição característica". Como observam os pesquisadores do grupo de Genebra, Dolz, Noverraz e Schneuwly (2004, p. 97), as características dos gêneros são estabelecidas de acordo com a recorrência das experiências de seu uso:

Os textos escritos ou orais que produzimos diferenciam-se uns dos outros e isso porque são produzidos em condições diferentes. Apesar dessa diversidade, podemos constatar regularidades. Em situações semelhantes, escrevemos textos com características semelhantes, que podemos chamar de gêneros de textos (ênfase dos autores).

Segundo Bronckart (2003, p. 54-55), os falantes não têm dificuldades em identificar esses gêneros:

[...] todo membro de uma comunidade linguística é confrontado com um universo de textos “já vistos", universo organizado em "gêneros" empíricos e históricos, ou seja, em formas de organização concretas que se modificam com o tempo. A confrontação com esses gêneros preexistentes produz nos leitores um certo conhecimento intuitivo de suas regras e propriedades específicas, conhecimento de senso comum.

A discussão sobre os gêneros textuais ou discursivos e sua incorporação ao ensino/aprendizagem de línguas não é recente. No final dos anos 1970, com o desenvolvimento da abordagem comunicativa como metodologia de ensino de línguas estrangeiras, os documentos ditos "autênticos" - e com eles os gêneros que circulam na sociedade - passaram a integrar os materiais didáticos, como forma de trazer a língua em uso, as situações de comunicação reais e os textos nelas produzidos para a sala de aula. Fez parte dos objetivos comunicativos, a partir de então, ler e produzir biografias, avisos, cartas de reclamação, receitas, convites e tantos outros textos que pertencem a diversos gêneros do discurso.

\footnotetext{
7 Apesar da diferença existente entre essas noções, os termos "gêneros discursivos" e "gêneros textuais" são empregados aqui de forma indistinta, na medida em que o trabalho em sala de aula exige que se dê atenção ora à dimensão discursiva ora à textual.
} 
Entre os estudiosos que apontam para a importância da exploração de gêneros no ensino de línguas, Marcuschi (2002, apud ARRUDA, 2012, p. 141) "sustenta que quando dominamos um gênero textual, dominamos uma forma de realizar linguisticamente objetivos específicos em situações sociais particulares".

Outro aspecto relevante para nosso estudo é que, apesar de sua grande diversidade e da impossibilidade que se tem de definir uma progressão do ensino com base em uma lista fechada de gêneros, esses "podem ser agrupados em função de um certo número de regularidades linguísticas e de transferências possíveis" (DOLZ, NOVERRAZ, SCHNEUWLY, 2004, p. 120). Essa proposta de agrupamento de gêneros acontece de acordo com as capacidades de linguagem dominantes identificáveis em cada gênero: narrar, relatar, argumentar, expor, descrever ações.

\begin{tabular}{|c|c|}
\hline $\begin{array}{l}\text { ASPECTOS TIPOLOGICOS } \\
\text { Capacidades de linguagem } \\
\text { dominantes }\end{array}$ & $\begin{array}{l}\text { Exemplos de generos orais } \\
\text { e escritos }\end{array}$ \\
\hline $\begin{array}{l}\text { NARRAR } \\
\text { Mimesis da ação através da criação } \\
\text { de intriga }\end{array}$ & $\begin{array}{l}\text { Conto maravilhoso } \\
\text { rábula } \\
\text { Lenda } \\
\text { Narrativa de aventura } \\
\text { Narrativa de ficção científica } \\
\text { Narrativa de enigma } \\
\text { Novela fantástica } \\
\text { Conto parodiado... }\end{array}$ \\
\hline $\begin{array}{l}\text { RELATAR } \\
\text { Representação pelo discurso de } \\
\text { experiências vividas, situadas no } \\
\text { tempo }\end{array}$ & $\begin{array}{l}\text { Relato de experiência vivida } \\
\text { Relato de viagem } \\
\text { Tcotcmunho } \\
\text { Curriculum vitae } \\
\text { Notícia } \\
\text { Reportagem } \\
\text { Crônica esportiva } \\
\text { Ensaio biográfico... }\end{array}$ \\
\hline $\begin{array}{l}\text { ARGUMENTAR } \\
\text { Gustentação, refutação e negociação } \\
\text { de tomadas de posição }\end{array}$ & $\begin{array}{l}\text { Texto de opinião } \\
\text { Diálogo argumentativo } \\
\text { Carta do leitor } \\
\text { Carta de reclamação } \\
\text { Deliberação informal } \\
\text { Debate regrado } \\
\text { Discurso de defesa (adv.) } \\
\text { Discurso de acusação (adv.) }\end{array}$ \\
\hline $\begin{array}{l}\text { BXPOR } \\
\text { Apresentação textual de diferentes } \\
\text { formas dos saberes }\end{array}$ & $\begin{array}{l}\text { Seminário } \\
\text { Conferência } \\
\text { Artigo ou verbete de } \\
\text { enciclopédia } \\
\text { Entrevista de especialista } \\
\text { Tomada de notas } \\
\text { Resumo de textos } \\
\text { "expositivos" ou explicativos } \\
\text { Relatório científico } \\
\text { Relato de experiência } \\
\text { cientifica }\end{array}$ \\
\hline $\begin{array}{l}\text { DESCREVER A ÇÕES } \\
\text { Regulação mútua de } \\
\text { comportamentos }\end{array}$ & $\begin{array}{l}\text { Instruções de montagem } \\
\text { Receita } \\
\text { Regulamento } \\
\text { Regras de jogo } \\
\text { Instruções de uso } \\
\text { Instruções }\end{array}$ \\
\hline
\end{tabular}

Figura 1 - Agrupamento de gêneros de acordo com as capacidades de linguagem dominantes Fonte: extraído de Dolz, Noverraz e Schneuwly (2004, p. 121).

A Figura 1 sintetiza a proposta de agrupamento de gêneros de acordo com as capacidades de linguagem dominantes, com a ressalva de que é "Não é possível classificar um gênero de maneira absoluta num dos agrupamentos propostos" (DOLZ, NOVERRAZ, SCHNEUWLY, 2004, p. 121). Retomaremos esse agrupamento, em nossa análise das tarefas do Celpe-Bras, mais adiante.

Ao defender o uso de gêneros textuais no ensino/aprendizagem das línguas estrangeiras, Arruda (2012, p. 141) observa que "quanto maior for o conhecimento de gêneros diversos, mais possibilidades os aprendizes terão de agir adequadamente com a linguagem em diferentes situações". Por isso, a avaliação das competências interacionais também passou a incorporar as situações de uso e os gêneros que elas mobilizam, como é o caso nas tarefas do exame Celpe-Bras. 
Em uma certificação da proficiência como a que propõe o Celpe-Bras, o uso dos gêneros é particularmente justificado, visto que, no cotidiano, os examinandos precisam demonstrar capacidades de agir e interagir socialmente em língua portuguesa. Todavia, definir como será feita essa certificação não resolve o problema do trabalho cotidiano em sala de aula e o da apropriação dos critérios pelos estudantes que serão, em pouco tempo, submetidos ao exame. Como articular o trabalho realizado em sala de aula e o modo como os elaboradores do exame encaram a avaliação das competências discursivas dos examinandos? Este é o problema da avaliação formativa, que abordaremos a seguir.

\section{Avaliação formativa e ensino-aprendizagem da escrita}

O Guia do Participante esclarece o direcionamento adotado para a avaliação, ressaltando a integração dos parâmetros de avaliação com os de recepção/produção: “São os elementos da tarefa que delimitam para o examinando as condições de leitura e escrita, construindo um texto pertencente a determinado gênero do discurso, ao mesmo tempo em que fornecem os parâmetros para a avaliação" (BRASIL, 2013, p. 7).

A correção da parte escrita da prova se dá de maneira holística, sendo considerados três eixos de análise: “[...] adequação ao contexto (cumprimento do propósito de compreensão e de produção, levando em conta o gênero discursivo e o interlocutor), adequação discursiva (coesão e coerência) e adequação linguística (uso adequado de vocabulário e de estruturas gramaticais) (BRASIL, 2012, p. 8 - grifos nossos). Os diversos manuais e guias produzidos pelo INEP apresentam os critérios gerais que direcionam a avaliação das produções, como exposto acima. Porém, não detalham parâmetros desenvolvidos para cada tarefa, justamente por serem específicos a cada tarefa.

Como indicamos inicialmente, nosso propósito, neste estudo, era o de criar subsídios para orientar o trabalho de professores e alunos em aulas de preparação ao exame, de duas maneiras articuladas: a primeira consistia em disponibilizar indicações das características mais recorrentes das situações de comunicação encontradas nas tarefas do exame. A segunda era de permitir associar a esse conhecimento uma efetiva avaliação formativa ao longo desse período de preparação, embasada na construção adequada dos critérios, pelos professores-estagiários bem como pelos alunos, em cada tarefa avaliada.

Segundo lembra Cunha (2006), a avaliação formativa serve a finalidades pedagógicas, isto é, ela é "essencialmente voltada para a regulação da aprendizagem" ou, nas palavras de Hadji (2001, p. 20): "a avaliação torna-se formativa na medida em que se inscreve em um projeto educativo específico, o de favorecer o desenvolvimento daquele que aprende", quando, ao longo da ação pedagógica, desempenha uma função de regulação - sua mais importante característica, segundo o autor - e permite aos atores analisar suas ações e modificá-las na direção dos objetivos almejados.

Os critérios de avaliação dos textos produzidos na Parte Escrita são claramente expressos e até ilustrados em provas comentadas, disponibilizadas pelo INEP (BRASIL, 2013). A leitura desses comentários, no entanto, é raramente suficiente para orientar o trabalho dos professoresestagiários que não têm o hábito de lidar com produções textuais nessa perspectiva, nem para direcionar o esforço dos próprios alunos que precisam entender como melhorar seu desempenho para conseguirem a certificação mínima (Intermediária). Adotar uma perspectiva formativa, no trabalho em sala de aula, apresenta-se, então, como importante estratégia para que os estudantes entendam quais as competências exigidas e possam desenvolvê-las, apropriando-se dos critérios de avaliação e autorregulando suas produções escritas, bem como seu modo de estudar. De fato, na avaliação formativa em língua, a participação dos aprendentes é essencial:

[...] solicita-se do aprendente que desenvolva uma atividade analítica sistemática e que, ao objetivar textos seus, de pares ou de autores confirmados, passe a tomar consciência dos problemas de diversas ordens (discursiva, enunciativa, linguística etc.) para os quais se precisa responder constantemente na elaboração textual (CUNHA, 2012, p. 124). 
Isso significa que a construção dos critérios e de seus descritores exige um trabalho de conscientização dos participantes (professores-estagiários e alunos) a respeito das características esperadas e uma colaboração constante entre pares, bem como entre professores e alunos, para que sejam evidenciados problemas e soluções na escrita dos gêneros.

É no intuito de ajudar estagiários e futuros examinandos a melhor se situarem em relação às características predominantes apresentadas pelas tarefas de produção escrita e, portanto, a poderem se valer de práticas de avaliação formativa, que foi empreendido o estudo das tarefas do exame Celpe-Bras, conforme metodologia descrita a seguir.

\section{Metodologia}

A investigação foi realizada com base em uma abordagem quali-quantitativa de caráter documental, na medida em que se buscou descrever a realidade das tarefas inseridas no acervo de documentos do exame. Embora se tivesse lançado mão de certa quantificação, para melhor dimensionar os fenômenos que emergiam da análise dos dados documentais, a realidade a ser descrita e compreendida não cabia em categorias pré-moldadas, mas exigia uma interpretação por parte dos pesquisadores, como veremos logo adiante (ANDRÉ, 2011).

Concomitantemente com a leitura de uma bibliografia acerca da produção textual, de seu ensino bem como de sua avaliação, foi coletado o material documental pertinente para este estudo, isto é:

- Documentos sobre a organização da produção escrita no Exame Celpe-Bras e sua avaliação (manuais e guias de orientação produzidos pela Comissão Científico-Técnica que elabora as provas e dirige sua avaliação);

- Tarefas da parte escrita elaboradas nos últimos dez anos, que se encontram disponibilizadas no acervo CELPE-Bras online ${ }^{8}$. Foi feita a coleta de todas as provas dos últimos dez anos (2005-2015) do exame Celpe-Bras, num total de 22 sessões e 88 tarefas?

Com base, por um lado, nas concepções teóricas que embasam a proposta de avaliação da proficiência em Português do Celpe-Bras e, por outro, nas indicações dos manuais e guias, foram definidas categorias que permitiram evidenciar suas características predominantes das tarefas, conforme exposto no Quadro 1. Essas categorias passaram a compor um quadro de classificação realizado em uma planilha do programa Excel $^{10}$. Cada tarefa foi analisada e as informações depreendidas devidamente tabuladas.

O preenchimento das categorias em cada uma das tarefas mostrou-se difícil, por diversas razões. Uma delas é que o comando da tarefa nem sempre indica um direcionamento explícito para a categorização que pretendíamos fazer. Por exemplo, não especifica sempre o gênero ao qual pertence o texto a ser produzido, pedindo apenas para "escrever um texto". Foi preciso dar uma interpretação para este termo, pois agrupá-los na categoria "não indicado" não seria de grande ajuda para o nosso propósito. Por exemplo, entendemos que o "texto" que deveria ser encaminhado às empresas do bairro, pedindo patrocínio (tarefa 2005/1-3) poderia ser uma carta.

\begin{tabular}{|l|l|}
\hline \multicolumn{1}{|c|}{ CATEGORIA } & DESCRIÇÃO \\
\hline $\begin{array}{l}\text { Gênero ao qual pertence o texto a } \\
\text { ser construído }\end{array}$ & Gênero discursivo solicitado na tarefa. \\
\hline Meio de circulação & Meio/lugar em que o texto a ser construído irá circular. \\
\hline Enunciador & Pessoa/instituição que assume a autoria do texto. \\
\hline
\end{tabular}

\footnotetext{
${ }^{8}$ http://www.ufrgs.br/acervocelpebras

${ }^{9}$ Cada tarefa foi identificada pelo ano de realização do exame, pelo numero da sessão do exame (são duas sessões anuais) e pelo número da tarefa na sessão (são quatro tarefas por sessão). Por exemplo, a tarefa 2014-1/3 é a terceira tarefa da primeira sessão de realização do exame, no ano de 2014.

${ }^{10}$ Este programa constitui uma ferramenta útil para a tabulação dos dados, porque oferece a opção de filtrar, que nos ajudou com a quantificação dos resultados obtidos nos agrupamentos das tarefas.
} 


\begin{tabular}{|l|l|}
\hline Interlocutor & Pessoa/instituição ao qual o texto será dirigido. \\
\hline Propósito & Finalidade da tarefa. \\
\hline Grupo de gênero ao qual pertence & $\begin{array}{l}\text { Propósito predominante da tarefa (de acordo com o agrupamento } \\
\text { de gêneros do grupo de Genebra). }\end{array}$ \\
\hline Nível de formalidade & Grau de formalidade do texto a ser elaborado. \\
\hline
\end{tabular}

Outra razão pelas dificuldades encontradas nessa classificação é que não basta o gênero ser definido para que se saiba qual o propósito predominante na tarefa: pode-se, por exemplo, escrever uma carta para relatar, expor ou solicitar, entre outros. Além disso, a categoria "propósito" revelou uma grande diversidade, tornando assim mais difícil realizar a síntese pretendida com o uso do agrupamento de textos. Em muitas tarefas, de fato, o comando parece indicar vários propósitos, como é o caso da tarefa 2013/2-2: “Incentivar os diretores de escola a participarem do programa, apresentando o programa e argumentando sobre os benefícios do programa para a escola e a sua comunidade" (grifos nossos). Neste caso, é preciso expor informações e argumentos, para incentivar os interlocutores a agir, mas o texto realizado terá características mais argumentativas. Por isso, essa tarefa foi inserida na categoria "argumentar".

Apesar do grande número de entradas que resulta da inserção dos dados na planilha, a tabulação desses dados revela linhas gerais que apresentaremos agora, ao analisar cada categoria e discutir os dados.

\section{Análise e discussão dos dados}

No que diz respeito aos gêneros discursivos solicitados, foram computados um total de 20 gêneros diferentes ${ }^{11}$, nas 88 tarefas. Porém, nove dos gêneros encontrados são representados apenas por uma ocorrência, pelo que decidimos repertoriá-los na categoria "outros" ${ }^{12}$.

Sobraram, então, 12 gêneros distintos que aparecem, no quadro 2, por ordem decrescente de ocorrência.

\begin{tabular}{|c|c|}
\hline Gênero solicitado & Número de ocorrências \\
\hline Carta & 17 \\
\hline Artigo informativo & 12 \\
\hline E-mail & 9 \\
\hline Informativo & 9 \\
\hline Artigo de opinião & 8 \\
\hline Carta do leitor & 6 \\
\hline Apresentação & 6 \\
\hline Mensagem & 4 \\
\hline Texto de panfleto & 3 \\
\hline Texto publicitário & 3 \\
\hline Carta aberta & 2 \\
\hline Outros & 9 \\
\hline Total & $\mathbf{8 8}$ \\
\hline
\end{tabular}

Quadro 2 - Classificação dos gêneros encontrados pelo número de ocorrências

Em relação à recorrência dos gêneros solicitados nas tarefas, observa-se, como mostra o gráfico 1, que, embora seu número seja elevado, na realidade, do ponto de vista da estrutura, sobressaem amplamente os gêneros da correspondência: carta, e-mail, mensagem, carta aberta,

11 Os gêneros encontrados foram: apresentação, artigo de opinião, artigo informativo, carta, carta aberta, carta do leitor, convite, diário de viagem, editorial, e-mail, guia de orientação, informativo, introdução de um processo judicial, mensagem, narrativa, panfleto, texto publicitário, relatório, resposta a um questionário, resumo.

12 Trata-se dos seguintes gêneros: convite, diário de viagem, editorial, guia de orientações, introdução de processo judicial, narrativa, relatório, respostas a um questionário e resumo. 
carta do leitor, que constituem, juntos, $43,2 \%$ do total, como mostra o Gráfico 1. Provavelmente sejam esses os gêneros mais usados pelo cidadão comum em suas interações escritas, o que justifica que estejam presentes em um maior número de tarefas.

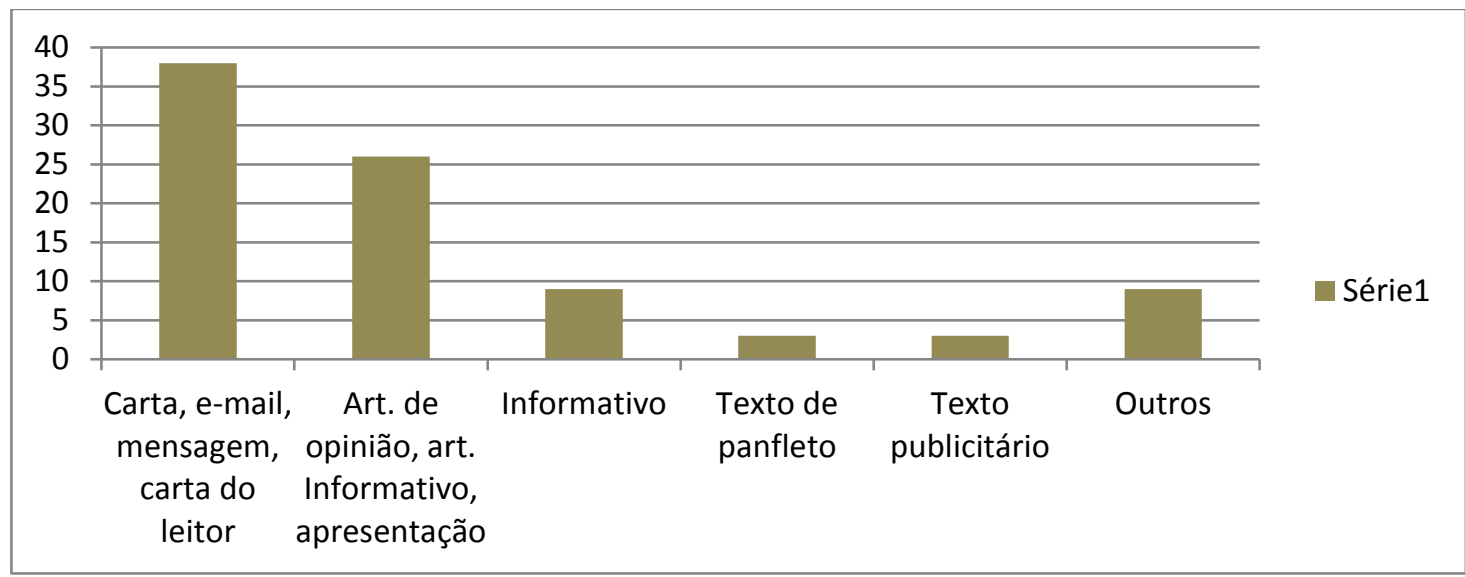

Gráfico 1 - Nível de recorrência de gêneros

Para percebermos o tipo de propósito predominante nas tarefas do corpus, os gêneros solicitados também foram classificados em um dos cinco agrupamentos de gêneros propostos pelo grupo de Genebra (ver Fig. 1 já apresentada).

O Gráfico 2 mostra os resultados obtidos, ilustrando que metade dos textos solicitados pertence ao grupo do "argumentar" (50\%), seguida pela categoria "expor" (38,7\%) e "descrever ações" $(7,9 \%)$. A categoria "relatar" $(2,3 \%)$ é representada por duas ocorrências e a categoria "narrar" $(1,1 \%)$, por apenas uma. Pode-se afirmar que os textos mais frequentemente solicitados pertencem, portanto, aos gêneros do argumentar, do expor e do descrever/prescrever ações.

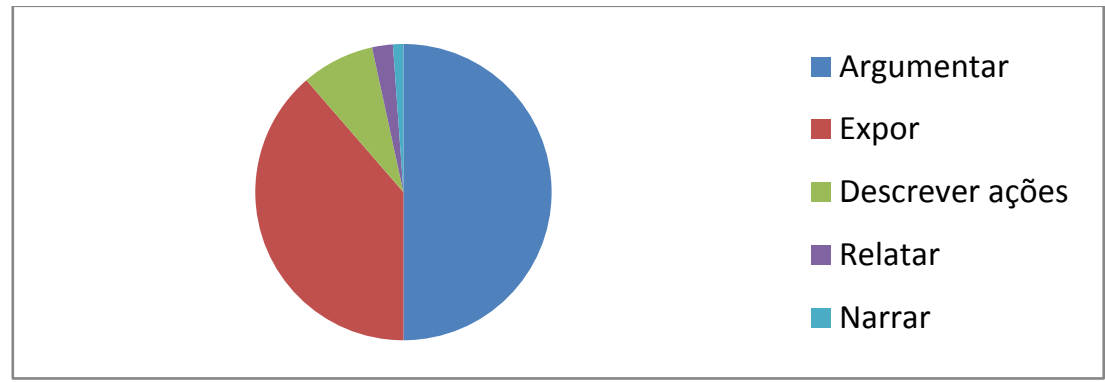

Gráfico 2: Agrupamento de gêneros

Cruzando esse dado com aqueles obtidos anteriormente sobre os gêneros, podemos perceber melhor ainda quais características predominam na maioria das tarefas do corpus. O grupo "Argumentar" concentra gêneros como e-mail, artigo de opinião, carta do leitor, carta, já que o propósito principal das referidas tarefas é de convencer alguém a agir com base nos argumentos apresentados. No grupo "Expor", por sua vez, encontram-se predominantemente gêneros como artigo informativo, informativo e apresentação, o que não surpreende.

As outras categorias - "meio de circulação" (do texto a ser produzido), "enunciador" e "interlocutor" - serviram como principais indicadores para se determinar o nível de formalidade exigido. Analisaremos cada um a seguir.

Foram repertoriadas 16 categorias para a rubrica "meio de circulação", porém, na apresentação gráfica dos dados (Quadro 3), decidiu-se por agrupar no tópico "outros" as categorias com apenas uma ocorrência - boletim informativo, caderno de respostas em uma enquete, cardápio e pôster por serem bastante específicas e, portanto, pouco usuais.

Em 11 casos, o comando da tarefa não especifica onde o texto irá circular, mas a informação parece secundária em relação ao gênero solicitado (uma carta, um informativo ou um panfleto, por exemplo) e ao interlocutor (o diretor, clientes ou o público em geral). Nos nove casos em que o 
comando pede para escrever uma solicitação ou escrever para alguém, embora o meio de circulação não seja especificado, fica claro que se trata de uma correspondência, quer impressa, quer eletrônica. Essas rubricas são repertoriadas com o respectivo quantitativo no quadro 3:

\begin{tabular}{|l|c|}
\hline Revista / jornal & 22 \\
\hline Site / Blog & 10 \\
\hline Correio/carta & 12 \\
\hline Correio eletrônico/e-mail & 9 \\
\hline $\begin{array}{l}\text { Mensagem em meio de correspondência não } \\
\text { especificado }\end{array}$ & 9 \\
\hline Mural & 3 \\
\hline Catálogo & 2 \\
\hline Guia & 2 \\
\hline Livro & 2 \\
\hline Quadro de avisos & 2 \\
\hline Outros & 4 \\
\hline Não especificados & 11 \\
\hline \multicolumn{1}{|c|}{ Total } & $\mathbf{8 8}$ \\
\hline
\end{tabular}

Quadro 3 - Classificação dos meios de circulação dos textos a serem produzidos

Nota-se que, quando são especificados, os meios de circulação preferenciais propostos nas tarefas são a mídia impressa e virtual (num total de 32), em que o autor do texto se dirige a um público de leitores, e os meios de correspondência - cartas, e-mails ou mensagens - (num total de 30) nos quais é preciso se dirigir a uma pessoa em particular ou a um grupo de pessoas específico. Fica claro, todavia, que essas rubricas não constituem em si uma indicação das características do texto que será produzido. Ainda é preciso levar em conta as informações dadas no comando em relação ao enunciador e ao interlocutor.

A tabulação dos dados nas categorias "enunciador" e "interlocutor" (apresentadas nos quadros 4 e 5 , respectivamente) mostra uma grande variedade de situações. De fato, são 33 papéis diferentes que o examinando pode assumir nas tarefas, de chefe de uma biblioteca comunitária a publicitário, entre os quais quase a metade só aparece uma vez entre as 88 tarefas.

\begin{tabular}{|c|c|c|c|c|}
\hline $\begin{array}{l}\text { Categoria mais } \\
\text { geral }\end{array}$ & Categoria específica & Subtotal & $\begin{array}{c}\text { Total } \\
\text { Ocorrências }\end{array}$ & Percentual \\
\hline \multirow{7}{*}{$\begin{array}{c}\text { Papéis assumidos na } \\
\text { vida pelo } \\
\text { examinando }\end{array}$} & O próprio & 23 & \multirow{7}{*}{36} & \multirow{7}{*}{40,9} \\
\hline & Amigo & 3 & & \\
\hline & Leitor & 4 & & \\
\hline & Morador & 3 & & \\
\hline & Turista & 1 & & \\
\hline & Candidato & 1 & & \\
\hline & Consumidor & 1 & & \\
\hline \multirow{10}{*}{$\begin{array}{c}\text { Profissionais } \\
\text { diversos }\end{array}$} & Funcionário & 13 & \multirow{10}{*}{33} & \multirow{10}{*}{37,5} \\
\hline & Colunista/jornalista & 5 & & \\
\hline & Membro de associação & 4 & & \\
\hline & Professor & 3 & & \\
\hline & $\begin{array}{l}\text { Relações-públicas de uma editora / } \\
\text { restaurante }\end{array}$ & 2 & & \\
\hline & Publicitário & 2 & & \\
\hline & Editor de jornal & 1 & & \\
\hline & Escritor & 1 & & \\
\hline & Agente de viagem & 1 & & \\
\hline & Membro da equipe de divulgação & 1 & & \\
\hline \multirow{7}{*}{$\begin{array}{l}\text { Pessoa exercendo } \\
\text { cargo de } \\
\text { responsabilidade }\end{array}$} & Diretor de escola & 3 & \multirow{7}{*}{18} & \multirow{7}{*}{20,5} \\
\hline & Presidente de associação / entidade & 2 & & \\
\hline & Dono / gerente de agência de viagens & 2 & & \\
\hline & Proprietário de uma loja / restaurante & 2 & & \\
\hline & Responsável de programa social/ONG & 2 & & \\
\hline & Chefe da Biblioteca Comunitária & 1 & & \\
\hline & Síndico de condomínio & 1 & & \\
\hline
\end{tabular}




\begin{tabular}{|c|c|c|c|c|}
\hline & Diretor da agência de empregos & 1 & & \\
\hline & Gerente financeiro de agremiação & 1 & & \\
\hline & Gerente de Recursos Humanos & 1 & & \\
\hline & Responsável pelo setor de Relações Públicas & 1 & & \\
\hline & Responsável pela divulgação & 1 & & \\
\hline Outro & Personagem de uma crônica & 1 & 1 & 1,1 \\
\hline & TOTAL & 88 & 88 & 100 \\
\hline
\end{tabular}

Quadro 4 - Classificação dos enunciadores nas tarefas Celpe-Bras

O gráfico 3 apresenta mais sinteticamente o resultado do agrupamento desses diferentes enunciadores. Percebe-se que, em um número expressivo de 40,9\%, trata-se de papeis sociais que o examinando certamente já assume em sua vida real, sendo chamado a reagir "ele mesmo" em alguma situação ou enquanto amigo, consumidor ou turista.

Em 37,5\% dos casos, o examinando é chamado a assumir o papel de profissionais diversos (funcionário, jornalista...) e em 20,5\% das tarefas, o enunciador é alguém com cargo de responsabilidade (diretor, gerente...). Embora se possa pensar que tais enunciadores precisariam demonstrar competências específicas (publicitário, por exemplo), o foco do exame está, obviamente, na capacidade de uso da linguagem para alcançar os objetivos da tarefa.

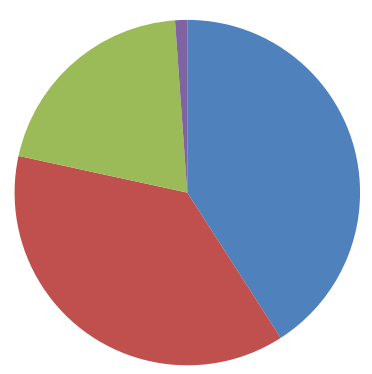

Papéis assumidos na vida
pelo examinando
Profissionais
Diversos
Pessoa exercendo cargo de
responsabilidade
Outro

Gráfico 3: Agrupamento das tarefas em função do interlocutor pretendido

Como vimos, também é importante saber a quem esses diversos enunciadores destinam o texto produzido. O quadro 5 elucida a questão, mostrando quem são os interlocutores mencionados nas tarefas e classificando-os em termos de frequência de ocorrência. Cruzando os dados do quadro 5 com os do quadro 4 , vemos que, em 40,9\% das tarefas, o enunciador é um cidadão comum, dirigindo-se ao público em geral não especificado (em 44,3\% das tarefas), o que se assemelha com a realidade dos examinandos, já que todos podem, de fato, cidadãos se encontrar a qualquer momento na situação de expressar uma opinião diante de um público indefinido (como é frequentemente o caso nas redes sociais) ou de fazer uma solicitação junto a uma instituição (repartição pública, associação...) ou a pessoas determinadas (autoridade, chefia...).

\begin{tabular}{|c|c|c|c|c|}
\hline Categoria mais geral & Categoria específica & Subtotal & $\begin{array}{c}\text { Total } \\
\text { ocorrências }\end{array}$ & Percentual \\
\hline \multirow{3}{*}{$\begin{array}{l}\text { Público em geral não } \\
\text { especificado }\end{array}$} & Leitores & 21 & \multirow{3}{*}{39} & \multirow{3}{*}{44,3} \\
\hline & Público em geral & 16 & & \\
\hline & Moradores & 2 & & \\
\hline \multirow{5}{*}{$\begin{array}{l}\text { Personalidade } \\
\text { Autoridade }\end{array}$} & Chefe/Diretor & 6 & \multirow{5}{*}{13} & \multirow{5}{*}{14,8} \\
\hline & Prefeito & 3 & & \\
\hline & Direção de escola & 2 & & \\
\hline & Vereador Alceu Brasinha & 1 & & \\
\hline & Fernando Brant & 1 & & \\
\hline \multirow{3}{*}{$\begin{array}{l}\text { Relacionamento } \\
\text { comercial ou de serviço }\end{array}$} & Clientes & 8 & \multirow{3}{*}{10} & \multirow{3}{*}{11,4} \\
\hline & Empresa de venda & 1 & & \\
\hline & Médico & 1 & & \\
\hline \multirow{3}{*}{$\begin{array}{l}\text { Público geral } \\
\text { especificado }\end{array}$} & Pais dos alunos & 2 & \multirow{3}{*}{7} & \multirow{3}{*}{7,95} \\
\hline & Comunidade escolar & 2 & & \\
\hline & Comunidade acadêmica & 1 & & \\
\hline
\end{tabular}




\begin{tabular}{|c|c|c|c|c|}
\hline & Alunos & 1 & & \\
\hline & Motoristas de taxi & 1 & & \\
\hline \multirow{2}{*}{$\begin{array}{c}\text { Relacionamento pessoal } \\
\text { ou com pares }\end{array}$} & Amigo(a) & 4 & \multirow{2}{*}{7} & \multirow{2}{*}{7,95} \\
\hline & Colegas de trabalho & 3 & & \\
\hline \multirow{3}{*}{ Instituição } & Empresas patrocinadoras & 4 & \multirow{3}{*}{7} & \multirow{3}{*}{7,95} \\
\hline & Associação & 2 & & \\
\hline & Instituição & 1 & & \\
\hline $\begin{array}{c}\text { Relação de } \\
\text { subordinação }\end{array}$ & Funcionários & 4 & 4 & 4,5 \\
\hline Outro & Comissão julgadora de prêmio & 1 & 1 & 1,2 \\
\hline & TOTAL & 88 & 88 & 100 \\
\hline
\end{tabular}

Quadro 5 - Classificação dos interlocutores nas tarefas Celpe-Bras

Com base no quadro de tratamento dos dados também podemos depreender qual registro de linguagem é solicitado de modo predominante na elaboração dos textos.

\begin{tabular}{|c|c|c|}
\hline Grau de formalidade & Total de ocorrências & Percentual \\
\hline Formal & 82 & 93,2 \\
\hline Informal & 6 & 6,8 \\
\hline TOTAL & $\mathbf{8 8}$ & $\mathbf{1 0 0}$ \\
\hline
\end{tabular}

Quadro 6- Grau de formalidade exigido nas tarefas Celpe-Bras

Quase que invariavelmente, o exame Celpe-Bras exige o registro formal, como observamos pelos números obtidos, no quadro 6 , na categoria "nível de formalidade". A própria atividade de escrita, em situações que envolvem domínios públicos, leva a um padrão mais culto.

A tentativa de classificação coerente dessas categorias nos levou a perceber que, tomadas isoladamente, elas não são significativas, mas que, ao contrário, o que importa são as relações entre quem escreve e para quem: escrever a um amigo, ao público em geral ou a uma personalidade não cria as mesmas obrigações ou restrições.

A partir dos dados aqui evidenciados, foi elaborada uma grade de avaliação (ver em apêndice) sintetizando os critérios indicados pelos elaboradores do exame, mas cujos descritores passaram a ser preenchidos e trabalhados coletivamente em sala de aula pelos alunos, com a ajuda dos estagiários, para que percebessem, em cada tarefa, as implicações, não apenas em termos de características do gênero, mas também em termos de análise dos outros elementos incluídos no contexto da tarefa.

Em sala de aula, quando se trabalha com uma tarefa de produção escrita, após o preenchimento coletivo dos descritores na grade, os alunos usam esse instrumento para realizar uma avaliação mútua em que, em duplas, analisam os textos produzidos pelos integrantes da dupla, verificando se as características esperadas do texto, em termos discursivos, textuais e linguísticos, se encontram efetivamente contempladas nele. Indicam sua avaliação, nas colunas apropriadas, pelos sinais seguintes: positivo $(+)$, quando consideram que os descritores elencados estão presentes em seu texto; "mais ou menos" $( \pm)$, quando consideram ter alcançado parcialmente o esperado; e negativo (-), quando não identificam os descritores em seu texto.

Com base nessas observações, devem reescrever seu texto individualmente, lançando mão da grade para uma autoavaliação consciente de seu texto. A grade também possibilita um confronto entre essas avaliações mútuas e/ou autoavaliações e a avaliação do professor. Na medida em que critérios e descritores vão sendo explicitados, a avaliação cumpre seu papel formativo.

A grade tem servido aos alunos, mas também aos estagiários, em sessões de formação pedagógica, levando-os a analisar as características de cada tarefa, e a elaborarem atividades de sala condizentes com o padrão Celpe-Bras. Outro aspecto importante é que, ao analisar os textos produzidos pelos estudantes estrangeiros com essa grade, todos deixam de se fixar apenas nos frequentes desvios linguísticos, o que certamente pode favorecer o desenvolvimento das capacidades linguístico-discursivas almejadas.

\section{CONCLUSÃO}


Nosso estudo das produções textuais do exame Celpe-Bras permitiu evidenciar o que o exame mais solicita em suas tarefas: os gêneros recorrentes, os propósitos mais frequentes, o tipo de enunciador e de interlocutor que aparecem mais regularmente nas tarefas e, por conseguinte, o registro linguístico predominante. Todavia, ao mostrar que a situação de comunicação precisa ser analisada em todos os seus elementos constitutivos, o estudo também ressalta a grande versatilidade e maleabilidade dos textos a serem produzidos no exame. Esses, embora pertençam a um gênero específico, não podem ser inseridos em um molde, nem o desenvolvimento das competências de produção pode satisfazer-se de uma descrição da estrutura dos gêneros, "uma vez que [...] os gêneros são caracterizados muito mais por suas funções comunicativas, cognitivas e institucionais do que por suas peculiaridades linguísticas e estruturais", como lembra Arruda (2012, p. 142).

Os dados obtidos no estudo aqui relatado constituíram, como era nosso objetivo, subsídios para os professores-estagiários que ministram as aulas nas turmas PEC-G. De posse dessas informações, foi construída a grade de avaliação que permite o uso de procedimentos de avaliação formativa. Os estagiários podem agora orientar os alunos com mais segurança em atividades de produção escrita ao longo dos meses de preparação ao exame. A elaboração de qualquer tarefa que tenha características semelhantes às do Celpe-Bras traz a necessidade, para professores e alunos, de analisar sistematicamente seus diferentes componentes discursivos (quem escreve, a quem, sobre o quê, com que propósito), além dos componentes textuais e linguísticos habitualmente considerados.

Isso também tem tornado possível uma avaliação formativa da escrita, na qual os diversos elementos identificados nessa análise são reinterpretados em termos de critérios (adequação contextual, com enunciador, destinatário, gênero e propósito etc.), e os critérios são "traduzidos" em forma de descritores que indiquem claramente em que medida o critério é alcançado. De certa forma, isso ajuda a sistematizar mais o trabalho em sala de aula e dá aos participantes das aulas (estagiários e estudantes estrangeiros), mais tranquilidade na hora de abordar essas tarefas e fará certamente, em médio prazo, diferença no desempenho dos estudantes.

Pretendemos dar sequência ao presente estudo, de modo a verificar em que medida os subsídios aqui levantados apoiam o desenvolvimento das capacidades de uso da língua pelos aprendentes estrangeiros e fomentam uma avaliação efetivamente formativa que leve todos os eles a uma aprendizagem bem sucedida.

\section{REFERÊNCIAS BIBLIOGRÁFICAS}

ANDRÉ, Marli Eliza D. A. de. Etnografia da Prática Escolar. 18.ed. Campinas, SP: Papirus, 2011.

ARRUDA, Climene F. Brito O ensino de LE por meio de análise de gêneros textuais: benefícios e dificuldades. In: DELL'ISOLA, Regina Lúcia Péret (Org). Gêneros textuais: o que há por trás do espelho? Belo Horizonte: FALE/UFMG, 2012.

BAKHTIN, Mikhail. Estética da criação verbal. São Paulo: Martins Fontes, 1997.

BRASIL. Ministério da Educação. INEP; Celpe-Bras. Postos aplicadores credenciados para aplicaşão do Celpe-Bras. Brasília: MEC/INEP/CELPE-Bras, 2016.

BRASIL. Ministério da Educação; INEP; Celpe-Bras. Guia do Participante: tarefas comentadas que compõem a edição de abril de 2013 do exame. Brasília: MEC/INEP/CELPE-Bras, 2013.

BRASIL. Ministério da Educação; INEP; Celpe-Bras. Manual do Aplicador. Brasília: MEC/INEP/ CELPE-Bras, 2012. 
BRONCKART, Jean-Paul. Gêneros textuais, tipos de discursos e operações psicolinguísticas. Rev. Est. Ling., Belo Horizonte, v. 11, n. 1, p. 49-69, jan. 2003.

CUNHA, Myriam Crestian. A sequência didática: renovação e mesmice em práticas de ensino/ aprendizagem do português. In: MENDES, E; CUNHA, JC. Práticas em sala de aula de línguas: diálogos necessários entre teoria(s) e ações situadas. Campinas, SP: Pontes, 2012.

. Nem só de conceitos vivem as transformações: equívocos em torno da avaliação formativa no ensino/ aprendizagem de línguas. Revista Brasileira de Lingü̈stica Aplicada, $\mathrm{n}^{\circ}$ 6, v. 2, 2006.

DOLZ, Joaquim; NOVERRAZ, Michelle; SCHNEUWLY, Bernard. Sequências didáticas para o oral e a escrita: apresentação de um procedimento. In: DOLZ, J; SCHNEUWLY, B. e colaboradores. Gêneros orais e escritos na escola. Trad. e org. de Roxane Rojo e Glaís Sales Cordeiro. Campinas, SP: Mercado das Letras, 2004.

HADJI, Charles. Avaliação desmistificada. Trad. de Patrícia C. Ramos. Porto Alegre: ArtMed, 2001.

MARCUSCHI, Luiz Antônio. Gêneros textuais: definição e funcionalidade. In: DIONÍSIO, Ângela Paiva; MACHADO, Anna Raquel; BEZERRA, Maria Auxiliadora (Org.) Gêneros textuais \& ensino. 5a. ed. Rio de Janeiro: Lucerna, 2007.

SCHOFFEN, J.R. Gêneros do discurso e parâmetros de avaliação de proficiência em português como língua estrangeira. 2009. 192f. Tese (Doutorado em Linguística aplicada). Instituto de Letras, Universidade do Rio Grande do Sul, Porto Alegre. 2000.

Recebido em 20/05/2017

Aceito em 21/07/2017

Publicado em 02/08/2017 


\section{APENDICE}

\section{FICHA DE AVALIAÇÃO DA PARTE ESCRITA - Simulado 1 - 05/2016 - TEXTO $1^{13}$}

Nome do estudante:

Nome do colega avaliador:

Nome do professor:

\begin{tabular}{|c|c|c|c|c|c|c|c|c|c|c|c|}
\hline & CRITÉRIOS & \multirow[t]{2}{*}{ DESCRITORES } & \multicolumn{3}{|c|}{ AVALIAÇÃO MÚTUA } & \multicolumn{3}{|c|}{ AUTOAVALIAÇÃO } & \multicolumn{3}{|c|}{ AVALIAÇÃO PROF } \\
\hline \multirow{6}{*}{ 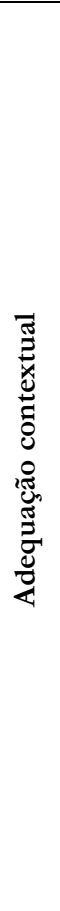 } & $\begin{array}{l}\text { Adequação do enunciador } \\
\text { [quem escreve?] }\end{array}$ & & - & +- & + & - & +- & + & - & +- & + \\
\hline & $\begin{array}{l}\text { Coordenador pedagógico de uma } \\
\text { escola de Educação Básica }\end{array}$ & $\begin{array}{l}\text { Assinatura: "Coordenador pedagógico" ou "Coordenação } \\
\text { pedagógica" } \\
\text { "Nós, da escola", "Nossa escola...”, “a Coordenação } \\
\text { pedagógica da nossa escola" } \\
\text { Obs.: a 1ª pessoa do singular não convém }\end{array}$ & & & & & & & & & \\
\hline & $\begin{array}{l}\text { Adequação ao interlocutor } \\
\text { [a quem?] }\end{array}$ & & & & & & & & & & \\
\hline & Aos pais dos alunos & $\begin{array}{l}\text { - Envolver os pais: "Prezados pais", "Senhores Pais" ou } \\
\text { vocativo "Pais"... } \\
\text { - Pronomes: "vocês", "seus filhos" } \\
\text { - Busca aproximação com o leitor. Pode ter o "nós": "nós, da } \\
\text { escola...", "nossos alunos". }\end{array}$ & & & & & & & & & \\
\hline & $\begin{array}{l}\text { Gênero textual } \\
\text { [que texto?] }\end{array}$ & & & & & & & & & & \\
\hline & Panfleto / informativo & $\begin{array}{l}\text { - Título que chama atenção } \\
\text { - Parágrafos curtos } \\
\text { - Conteúdo informativo dividido em tópicos com subtítulos } \\
\text { (eventualmente): "O que colocar na lancheira de seu filho"; } \\
\text { "Alimentos a serem evitados"... }\end{array}$ & & & & & & & & & \\
\hline
\end{tabular}

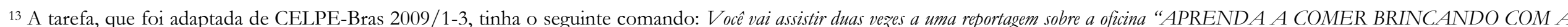

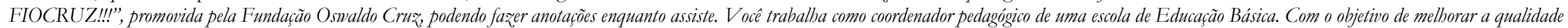

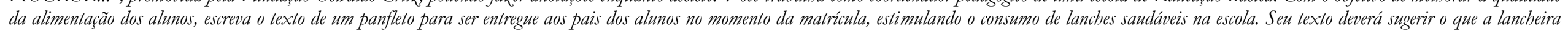
deve ou não conter, salientar a importância de criar bábitos alimentares saudáveis e apontar os inconvenientes do consumo de alimentos pouco saudáveis. 


\begin{tabular}{|c|c|c|c|c|c|c|c|c|c|c|c|}
\hline & $\begin{array}{l}\text { Propósito comunicativo } \\
\text { [para quê??] }\end{array}$ & & - & +- & + & - & +- & + & - & +- & + \\
\hline & $\begin{array}{l}\text { Estimular o consumo de lanches } \\
\text { saudáveis na escola } \\
\text { [Descrever ações] }\end{array}$ & $\begin{array}{l}\text { - Verbos no imperativo: "evitem comidas calóricas demais / } \\
\text { deem lanches saudáveis a ..." } \\
\text { - Verbos modais (dever, ser preciso, ser importante) } \\
\text { - Tom: não muito formal. }\end{array}$ & & & & & & & & & \\
\hline & $\begin{array}{l}\text { Conteúdo informacional do texto } \\
\text { [a respeito do quê?] }\end{array}$ & & & & & & & & & & \\
\hline & $\begin{array}{l}\text { Uso pertinente das informações do } \\
\text { texto provocador }\end{array}$ & $\begin{array}{l}\text { - Apontar inconvenientes do consumo de alimentos pouco } \\
\text { saudáveis (obesidade infantil que está aumentando. Hj } 18 \% \text { das } \\
\text { crianças brasileiras são obesas; doenças); } \\
\text { - Salientar a importância de criar hábitos saudáveis } \\
\text { (idade em que estão com mais fome e acabam ingerindo mais } \\
\text { calorias; restringir o consumo de alimentos não saudáveis: } \\
\text { sorvetes, chocolate, refrigerante); } \\
\text { - Mencionar o que a lancheira deve conter (frutas, sucos) ou } \\
\text { não (comidas calóricas, refrigerantes...). }\end{array}$ & & & & & & & & & \\
\hline & & & - & +- & + & - & +- & + & - & +- & + \\
\hline \multirow{2}{*}{ 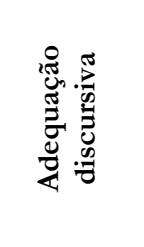 } & Coesão & $\begin{array}{l}\text { O texto está bem organizado. As ideias estão interligadas. O } \\
\text { uso dos conectivos é adequado. Pontuação correta. }\end{array}$ & & & & & & & & & \\
\hline & Coerência & $\begin{array}{l}\text { O que se diz não contradiz a proposta, nem há ambiguidades } \\
\text { e contradições internas. }\end{array}$ & & & & & & & & & \\
\hline 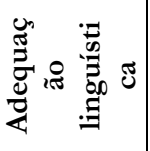 & Adequação lexical & $\begin{array}{l}\text { Elementos lexicais presentes: Alimentos saudáveis ou pouco } \\
\text { saudáveis / hábitos alimentares / comida / calorias / } \\
\text { nutrientes/ doenças / pessoas doentes / obesidade / crianças } \\
\text { obesas / }\end{array}$ & & & & & & & & & \\
\hline
\end{tabular}




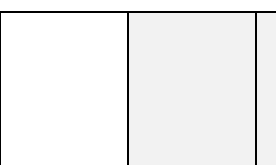

TIII

